\title{
Benchmarking the First Year Accounting Unit: Evidence from Australia
}

\author{
Nick Sciulli \\ Centre for Tourism and Services Research (CTSR) \\ School of Accounting, Victoria University \\ PO Box 14428, MCMC 8001, Melbourne, Australia \\ Tel: (03) 99194424 E-mail: nick.sciulli@vu.edu.au \\ Malcolm Smith \\ School of Accounting, Finance and Economics, Edith Cowan University \\ 270 Joondalup Drive \\ Joondalup WA 6027, Perth, Australia \\ Tel: (08) 63045263 E-mail: Malcolm.Smith@ecu.edu.au \\ Phil Ross \\ School of Accounting, University of Western Sydney \\ Locked Bag 1797 \\ Penrith South, NSW 1797 \\ Tel: (02) 9685-9451 E-mail: p.ross@uws.edu.au
}

\begin{abstract}
This paper compares some key organisational attributes of three accounting schools located at Australian universities. In addition, the content, structure and presentation of the first-year accounting unit is examined with a view to identifying best practices. Three Australian universities - one each from Western Australia, Victoria and New South Wales collaborated on this project. The heads of the respective schools supplied relevant data for school comparison purposes and a workshop meeting between the first year accounting unit co-ordinators provided data for a content analysis of their subject guides. The three schools had similar issues to manage. They include an aging staff profile, high use of casual academic staff and large student numbers across different campuses. Unsurprisingly, given the need for accreditation from professional accounting bodies, the content of the courses was very similar. However, there were significant differences in delivery and assessment, with potential implications for subject quality and resource use. The size and characteristics of the three universities investigated for this project do not reflect the profile of all accounting schools in Australia. The results of this benchmarking comparison has prompted managers to be aware of several critical issues identified to take appropriate action to remedy them. The authors are unaware of any previous benchmarking study comparing accounting schools at Australian universities and the findings can lead to better teaching and learning outcomes for first year accounting students.
\end{abstract}

Keywords: Benchmarking, Universities, Accounting courses

JEL classifications: M41, M40 and M49 


\section{Introduction}

The benchmarking project which forms the basis of this paper was initiated by the Business School Deans from the three participating universities - one each from Western Australia, Victoria and New South Wales (NSW). The driving force for the initiative was the need to respond to recommendations from the Australian Universities Quality Agency (AUQA) that universities undertake benchmarking as part of the quality assurance processes in their organisations. The main objective of this project was to compare the content, structure and operations of a large first year unit common to each institution. Further, data comparing academic staff and student demographics of the three schools of accounting would also be compared. The analysis was directed specifically towards two outcomes:

(a) indicating current best practice to provide the basis for improvement opportunities at each university, and

(b) confirming that appropriate standards were being applied by each university.

The unit chosen for detailed analysis at each institution was the first year introductory accounting unit that was compulsory for all students undertaking an undergraduate business major. The Heads of School of Accounting of the three participating universities met in July 2008 and established broad areas for detailed analysis and comparison for the accounting units.

The major inputs into the comparative process were conducted via email, with source documents circulated among the interested parties. Detailed analysis of the data was undertaken in face to face meetings in September and October 2008, attended by the Heads of School and the co-ordinators of the first year accounting units.

Detailed findings, and recommendations for future action, were reported to the respective Business Deans in November 2008.

The paper details differences across the three universities - designated as Case 1, Case 2 and Case 3. These differences occurred in areas of staff and student demographics, course content, course delivery and course assessment. The paper concludes with recommendations which may be applicable to heads of schools and colleagues in other disciplines as well as to university managers and policy makers. 


\section{Literature review}

Benchmarking is a process for identifying and implementing best practice at a particular point in time. There is currently a considerable volume of research on this management technique as highlighted by the work of Dattakumar and Jagadeesh (2003) in their review of the benchmarking literature. It is equally applicable to the private sector (see Kouzmin et al. 1999; Punniyamoorthy \& Murali 2008) and to the public sector (see for example, Vagnoni and Maran 2008; Wynn-Williams 2005). It is a tool that is used to identify best-practice and also, more importantly to gain an understanding of what processes are being utilised to achieve best practice. Thus, it is a system where best practices are identified and then, adopted by the organisation seeking to improve its activities. It has been used (most likely, incorrectly), interchangeably with terms such as business process engineering, total quality management and key performance indicators (KPIs) (Alstete 2008).

Bowerman et al (2002) makes a distinction between voluntary benchmarking which has an emphasis on continual improvement and defensive benchmarking which may seek to prove to an external authority that the organisation is not the worst performer. Alternatively, defensive benchmarking could be used to argue for more resources and/or prove to an audit authority that a recognised management technique is being utilised for improvement purposes. In fact in 2001 the UK Government went as far as establishing the Public Sector Benchmarking Service (PSBS) to encourage public sector agencies to adopt this management tool. Andersen, Henriksen and Spjelkavik (2008) suggest that the principal-agent theoretical framework can be applicable to benchmarking in the public sector context. In particular, benchmarking can be used to expose good or bad performance to the public with the objective of influencing the behaviour of both the agent and the agent's constituency, in this case, the students. Hence, students can then freely move to 'good' performing universities based in part, on the results of the benchmarking investigation.

A study conducted by Magd and Curry (2003) suggested that benchmarking is a key tool to use to achieve the goal of 'best value'. Best Value (BV) is a government initiative which replaced compulsory competitive tendering (CCT) in the local government sector. BV encourages local councils to form effective partnerships with the private sector and conferred a legal duty to provide value-for-money to users of their services. Investigating five (5) separate public sector case studies, Magd and Curry (2003) concluded that benchmarking could be used to assist the achievement of BV but that one significant barrier to its use was that benchmarking was viewed as setting up antagonistic competition between public sector providers of similar services.

Benchmarking is not a new technique to the university sector. In fact, comparisons of university performance based on teaching, research and student satisfaction are well documented and marketed as a tool for ensuring prospective students have access to data that can lead to informed choices regarding the selection of a suitable course of study. Pursglove and Simpson (2007) benchmarked the performance of English universities by dividing the universities into the Russell Group (research-oriented universities) and the post-1992 universities. They found that the post-1992 universities were more effective and efficient than the Russell group members, contrary to the ranking of these universities published in league tables. 
Accounting courses in Australia are subjected to various external regulatory and internal oversight to ensure that they meet the requirements of various stakeholders. Internal mechanisms include that university policies and procedures are adhered to, thus permitting academic boards/councils to approve courses brought to their attention. A powerful external compliance requirement is the need for universities to attain professional accreditation from the two professional accounting bodies in Australia, namely, CPA Australia and the Institute of Chartered Accountants of Australia (ICAA). It has been argued that professional body accreditation has led to a reduction in the scope and flexibility for the delivery of accounting courses in Australia (Mathews 2004).

Understanding clearly what the issues are regarding the teaching of a first year accounting unit is an important topic for academics, students and prospective employers. Jones and Sin (2005) found that almost a third of accounting students rated communication skills highly but that more of the non-accounting students placed communication skills first. These authors argue that unit course outlines need to incorporate generic/communication skills into ongoing student assessment. Similarly, Morgan (1997) found that practioners assigned a high importance to oral communication skills of active listening, constructive participation in meetings and one-to-one communication. One of the project aims for this investigation is to identify what and how students are assessed in their first year accounting unit.

In a UK study, Lucas (2003) surveyed 250000 accounting students. She found that the variety of accounting students studying introductory accounting caused problems, because academic staff found it problematic to change their teaching styles to teach masses of students with different entry levels. Some of the different characteristics of students included that English was not their first language, age, ethnic group, gender, socio-economic status and students from non-traditional backgrounds (Lyons 2006). Given this diverse student population, Malgwi (2006) surveyed 796 students at one university in the USA to ascertain whether there was merit in providing separate courses to students on the basis of whether they were intending to undertake an accounting major. The findings revealed a significant difference in the interest levels prior to, and after, undertaking the course. That is, the students undertaking a major in accounting showed more interest and confidence in taking their exams than non-accounting major students, suggesting that a separate stream should be considered. This conclusion is supported by the findings of Byrne and Flood (2008) of a positive association between academic performance and prior academic achievement and prior knowledge of accounting.

There remain gaps in the literature regarding specific staffing issues, such as the aging of the academic workforce and the capacity for future student research supervision. In addition, the changing landscape of the measurement of research performance will affect accounting academics. An assessment of the current state of these particular themes would be useful for departmental and university managers in addressing any required changes to policies and/or procedures. 


\section{Method}

As a consequence of the recommendations of AUQA, the Business School Deans of three Australian Universities decided to benchmark a large undergraduate unit. This would form the basis of future benchmarking exercises across different schools within the business faculty. To allow for valid comparisons, the three universities chosen were all post-Dawkins universities in that they were not established research oriented universities, but rather each had a history as a teaching university.

The first year accounting unit was chosen for the first benchmarking exercise because:

- It was the largest subject offered at each location

- The unit involved the use of a large number of full-time and casual staff compared with other disciplines, and

- The students enrolled in the subject comprised a diverse group which included full-time and part-time students, school leavers and mature-age students, local and international students and, students enrolled to gain a major in accounting whilst other students were intending to specialise in other disciplines.

The three heads of schools had some freedom in choosing what areas would be benchmarked. After numerous e-mail contacts and telephone conversations it was decided to benchmark the following areas:

1 Accounting staff demographics

2 First year student accounting demographics, and

3 First year accounting unit.

The rationale for selecting these three areas was that each of the schools had readily accessible data with which to make comparisons and that any changes made to the first year accounting unit could be used as a catalyst for relevant changes to other business units. .

Data for the accounting staff demographics were more difficult to obtain partly because the source data were scattered across various sections of the school, faculty, and held centrally by the university. Moreover, the data were not presented in a form that was tailored for easy comparisons with other accounting schools at other universities. For the staff demographics, source data were obtained from information held within the office of the head of school, as well as information collected from the human resources department. Direct contact was made with other academic school staff where clarifications were required and where recently employed staff did not have all of their previous academic history recorded electronically by the respective school.

The first year accounting student demographics data were collected from the faculty and cross-referenced with school data for accuracy. The first year accounting unit subject guide was used as the basis for a comparison of this subject across the three universities. Moreover, a workshop was scheduled at one of the universities where the first-year accounting unit co-ordinators identified challenges in administering the unit, identified any major differences in unit content and how the assessment tasks differed. The data were then tabulated in a spreadsheet format to allow for easy 
comparison between the three universities.

\section{Findings and discussion}

\subsection{Accounting Staff Demographics}

In terms of staff numbers, Case 1's accounting discipline has approximately one third the staff of Case 3 and Case 2 - numbers consistent with the size of their respective student enrolments. Both Case 1 and Case 2 had relatively high numbers of male staff (64\% and 76\% respectively), whereas Case 3 had $53 \%$ of its staff as female. The majority of staff are employed at Lecturer or Associate Lecture levels (Case $155 \%$; Case $383 \%$; Case 276\%). All three universities had very low numbers of staff at the Associate Professor and Professor level. Case 3 did not have any staff at these senior levels.

The age profile of accounting academic staff (see Table 1) showed Case 3 to be the only employer of staff in the 20-29 age group, though this only accounted for $8 \%$ of its total staffing. All universities in the study had difficulty in recruiting and retaining younger people for a career in academia. This reflected the requirement that prospective employees should have a higher degree qualifications (ideally a $\mathrm{PhD}$ ) before being considered appointable. It is interesting to note that $46 \%$ of staff at Case 1 are in the $60+$ age bracket and 56\% of staff at Case 3 are in the 50-59 age bracket. These profiles will need to be monitored carefully across the sector as more staff move into retirement or elect to take an early voluntary retirement package.

Understanding staffing demographics is important with respect to all accounting subjects, but perhaps even more so to introductory accounting. That is because of the high use of sessional teaching staff in the first year accounting unit and the difficulty of attracting highly competent staff willing to co-ordinate such a large subject across various campus locations.

Table 1. Age of Permanent Academic Staff.

\begin{tabular}{|c|c|c|c|c|c|c|}
\hline & \multicolumn{2}{|c|}{ Case 1} & \multicolumn{2}{|c|}{ Case 2} & \multicolumn{2}{|c|}{ Case 3} \\
\hline & Number & $\%$ & Number & $\%$ & Number & $\%$ \\
\hline \multicolumn{7}{|l|}{ Age } \\
\hline $20-29$ & 0 & 0 & 0 & 0 & 3 & 8 \\
\hline 30-39 & 1 & 9 & 7 & 24 & 2 & 6 \\
\hline $40-49$ & 3 & 27 & 11 & 38 & 10 & 28 \\
\hline $50-59$ & 2 & 18 & 9 & 31 & 20 & 56 \\
\hline $60+$ & 5 & 46 & 2 & 7 & 1 & 2 \\
\hline TOTAL & 11 & 100 & 29 & 100 & 36 & 100 \\
\hline
\end{tabular}


Staff demographics have significant implications for the research performance of the three participating universities. Each of the three participating university departments has a high proportion of non-researchers in their accounting school: $86 \%$ for Case 3, 36\% for Case 1 and 35\% for Case 2. Recent literature such as (Smith, Whale \& Noronha, 2008) places all three universities in the bottom half of the rankings for Australian schools of accounting.

The benchmark data provide evidence to explain such a situation:

- a paucity of senior staff across all three institutions, with Case 3 notable in having no appointments at professorial levels

- the absence of experienced researchers in senior positions to lead by example, and to mentor colleagues, is clearly apparent. While Case 1 and Case 2 both benefit from the publication activities of a small number of prolific individuals at a senior level, in their absence, Case 3 performs relatively poorly, and

- since the supervision of higher degree by research candidates, particularly at doctoral level, is normally predominantly undertaken by those at professorial levels, then this impacts on Higher Degree Research (HDR) completions across the three universities, with again, a relatively small number of individuals carrying out this activity.

Thus, senior positions appear to drive research performance and set the appropriate tone for the development of a research culture, and attract new research appointments. All three universities need to make senior appointments of research-active individuals if their research performance is to improve. The precarious age profile of Case 1 also suggests that they need to appoint younger research-active staff. In this regard, Table 2 highlights that Case 2 is currently the stand-out performer, with a healthy cluster of young academics pursuing doctoral qualifications. However, if Case 2, and to a lesser extent Case 1 and Case 3, are to hold on to their active, qualified researchers, then current perceptions of their being 'feeders' for more established institutions in their states must change. 
Table 2. Number of Active Researchers in School of Accounting, 2007.

\begin{tabular}{|c|c|c|c|c|c|c|}
\hline & \multicolumn{2}{|c|}{ Case 1} & \multicolumn{2}{|c|}{ Case 2} & \multicolumn{2}{|c|}{ Case 3} \\
\hline & Number & $\%$ & Number & $\%$ & Number & $\%$ \\
\hline \multicolumn{7}{|l|}{ Active/Non Researchers } \\
\hline $\begin{array}{l}\text { Active Researchers (Enrolled } \\
\text { in } \mathrm{PhD} \text { ) }\end{array}$ & 1 & 9 & 12 & 41 & 1 & 3 \\
\hline $\begin{array}{l}\text { Active Researchers (Not } \\
\text { enrolled in } \mathrm{PhD} \text { ) }\end{array}$ & 6 & 55 & 7 & 24 & 4 & 11 \\
\hline Non Researchers & 4 & 36 & 10 & 35 & 31 & 86 \\
\hline TOTAL & 11 & 100 & 29 & 100 & 36 & 100 \\
\hline
\end{tabular}

None of the three universities made significant use of contract staff, though between $22 \%$ and $31 \%$ of staff were employed on a sessional (casual) basis. Although this percentage of sessional staff does not appear remarkably high, it may convert to a high number of sessional staff concentrated in one place. This proved to be the situation for both Case 3 and Case 2, with respectively 30 and 40 sessional staff commonly involved each semester in the teaching of their first-year accounting unit. These numbers have serious implications for students who require access to staff members for consultation, as well as for the timeliness of reporting between sessional and permanent staff, and ensuring consistency of presentation to students across the various sessional staff teaching across different campuses. In such situations the management of the unit becomes problematic as there was evidence from Case 3 of the unit co-ordinator being forced to prepare and distribute detailed lesson plans to tutorial staff to maintain a semblance of consistency of delivery. Disturbingly, some accounting subjects (though not Accounting 1) were co-ordinated entirely by sessional staff, with implications for the management approaches necessary to ensure appropriate levels of teaching and learning outcomes.

A significant difference existed in the proportions of mature age students, relative to school leavers, in the student cohort of accounting students. In Case 1, 80\% of students were mature-age compared with $48 \%$ for Case 3 and $42 \%$ for Case 2. Given the national trend of a declining percentage of school leavers undertaking a higher education qualification, these statistics indicate that more resources may need to be directed towards this mature-age group to meet these challenges.

\subsection{First Year Accounting Demographics}

Data from Table 3 demonstrate that significant numbers of mature age students may be returning to formal study after an absence from a structured learning environment. The needs of these students may differ markedly from school leavers. Careful management of this group would be required to minimise a 
potential large attrition rate. Conversely, there are significant potential benefits for students as a whole if the curriculum and teaching style harnesses the work/life experiences of this mature-age cohort. External students are very small in number throughout, but all universities had a significant proportion of mature-age students (relative to school leavers). These demographics in the first year unit indicate the complexity of teaching a first year unit since a significant number of students will not have English as their first language and an even larger proportion may be returning to study after a significant time lag. When combined with the problems referred to above with sessional staffing, notably lack of student access and absence of consistency, then language and confidence problems will likely pose additional pressures on the student cohort, affecting the confidence of the students and retention rates.

Table 3. Number of Mature-Age Students in First Year Accounting Unit

\begin{tabular}{|l|c|c|c|c|c|c|}
\hline & \multicolumn{2}{|c|}{ Case 1 } & \multicolumn{2}{c|}{ Case 2 } & \multicolumn{2}{c|}{ Case 3 } \\
\hline & Number & $\%$ & Number & $\%$ & Number & $\%$ \\
\hline Mature-age & 98 & 38 & 577 & 62 & 516 & 44 \\
\hline School Leaver & 158 & 62 & 356 & 38 & 656 & 56 \\
\hline TOTAL STUDENTS & 256 & 100 & $933 *$ & 100 & 1,172 & 100 \\
\hline
\end{tabular}

* Includes onshore students only.

\subsection{Course Content: First Year Accounting Unit}

The objectives and desired outcomes from each of the three courses are similar, with the major focus of each unit being in the areas of preparation and interpretation of basic financial information. All three units have a mix of financial accounting and management accounting with Case 2 and Case 3 spending three weeks on management accounting topics whilst Case 1 spend only two weeks on this area. The remainder of the course focuses on topics related to financial accounting with some minor variations but significantly, none of the three courses focus on the concept of debits and credits. This reflects the fact that all three courses have been developed to cater to the needs of students who are accounting and non-accounting majors.

All three universities had recognised the importance of inter-personal skills for business, and were addressing observed deficiencies in written and oral communications among the accounting student cohort. All had either begun, or were contemplating the introduction of 'skills based' units into the accounting curriculum.

At Case 3 this was limited to a single unit, teaching students practical skills for library database searches, written communication, literature evaluation, and an appreciation of cultural and ethical issues. In Case 2, the corresponding program provided three successive units which developed students' business knowledge, 
personal attributes and professional skills. The program for Case 1 comprised consecutive units in each year of the degree. Students were introduced to the concept of business, and were assisted in the acquisition of interpersonal and teamwork skills. Thus, while in Case 3, the skills course primarily focused on improving students' practical skills, those at Case 1 and Case 2 aimed to assist students to improve their leadership, assessment, decision-making and problem solving skills, in addition to practical business skills.

While the course at Case 1 was the most wide-ranging, it also had the most serious consequences for the structure of the business degree. Because of the limited scope for elective units within the bachelor degree course, there was no longer a common core of introductory-level business subjects applicable to all business students. Thus, while both Case 2 and Case 3 maintained a common-core, it was possible for a non-accounting major to graduate in business without ever having completed an accounting unit. (The same would be true, for example, of a non-marketing major -they need never have completed a marketing unit.)

\subsection{Delivery}

All three universities adopted a traditional 'lecture + tutorial' format, with the lecture used to impart knowledge, and the tutorial having a workshop/seminar structure to follow up, clarify and provide practice exercises.

All three universities had three hours of class contact per week over a 12 or 13-week semester to complete their introductory accounting unit. However, while both Case 1 and Case 2 had a two-hour lecture, with a one-hour tutorial, for Case 3 it was the opposite: a one-hour lecture and two hours of tutorial. The latter might be regarded as superior for learning purposes, especially given trends in student attendance (currently around $60 \%$ for lectures and $95 \%$ for tutorials). However, this structure is much more resource intensive, especially given the large number of tutorials necessary to conduct the Case 3 course. A cost-benefit evaluation of this alternative structure might be beneficial.

\subsection{Assessment}

The assessment structure for each unit was also similar with Case 1 and Case 2 having four assessment items while Case 3 has five assessment items. The weightings assigned to the assessment items are also similar with the main exception being that Case 3 has a final exam weighted at $45 \%$, whereas both Case 1 and Case 2 have a final exam weighted at $60 \%$. This difference is attributable (partly) to the fact that the final exam at Case 3 covers only the second half of the course (i.e., after the mid-semester test) while for Case 1 and Case 2 all topics covered are examinable in the final exam.

While assessment for all three universities comprised a summation of coursework and examinations, there were differences in how this structure was implemented. For Case 2 there was no exam threshold; marks across different components were totaled without weighting for whether they were individual time-constrained assessments or team-based assignments. Both Case 3 and Case 1, on the other hand, 
implemented examination thresholds - students had to achieve a grade on the final examination to pass the unit (45\% for Case 3 and $50 \%$ for Case 1) as well as achieving a 50\% overall mark.

The use of supplementary examinations provided a further point of difference in the area of assessment. Neither Case 1 nor Case 3 had any form of additional assessment for marginal failures, but Case 2 had a non-discretionary supplementary examination for all failing candidates scoring more than $40 \%$ overall. The combination of these last two factors undoubtedly contributed to low overall fail grades in the unit at Case 2 $21 \%$ compared to those at Case $3(26 \%)$ and Case $1(32 \%)$. There was also some evidence that the assessment (assignments and examination) in Case 1's first accounting unit were of a more difficult standard than the equivalents at Case 3 and Case 2; this may contribute to the higher unit failure rates experienced at Case 1.

\section{Concluding Remarks}

The benchmarking exercise has provided the opportunity to observe and analyse the consistency and diversity of accounting offerings at three Australian universities. The three participating universities are far from ideal for a benchmarking analysis due to differences in size, of staffing and student enrolments and departmental discipline focus. Thus, the findings are difficult to generalise across the wider population. Nonetheless they provide interesting observations which allow the specification of suggestions consistent with the objectives of the exercise.

There are several issues where the problems faced by the three universities are common or similar:

- The age profile is either already precarious, or trending in that direction. Urgent attention to succession planning is required;

- The proportion of senior staff (particularly at professorial level) is consistently small, with significant implications for leadership, mentoring and research performance. Additional senior appointments, ideally of research-active staff, are required;

- The mix of students (i.e., mature-age/school leaver; local/international; major/non-accounting major) in core courses poses particular difficulties, which will impact on student satisfaction;

- The size of the first-year accounting unit required the use of sessional, rather than permanent staff occasionally to potentially dangerous levels. The implications for the staff co-ordination burden and the student experience should not be underestimated. For such large courses, administrative assistance must be made available to avoid staff stress and burn-out.

Conversely, there were significant differences in the way the first-year accounting unit was delivered. The content of the units looked similar, but deeper analysis revealed differences in both the depth and mode of delivery, most notably: 
- Of the three universities only Case 1 did not have a common-core of business units. Non-accounting majors did not complete the first (compulsory) accounting unit, and correspondingly accounting majors did not necessarily complete first year management or marketing units;

- There were significant differences in the delivery of the first Accounting unit. Case 3 operated on a $(1+2)$ lecture/tutorial hours split, while both Case 1 and Case 2 operated on a $(2+1)$ split. While the former is more resource intensive, it may provide improved student learning outcomes;

- There were significant differences in assessment of the first accounting unit. Both Case 1 and Case 3 instituted an exam-performance threshold, so that students with $50 \%$ overall only passed the unit if they achieved a specified mark in the exam. No such threshold existed at Case 2; if the student accumulated $50 \%$ overall they passed the unit, irrespective of how poor their performance in the final examination.

Comparisons based on the numbers reported for student satisfaction with unit/teacher should be treated with caution, and are not detailed here, since they are based on different survey instruments. A future project might examine the development of a new instrument with common questions, in order to improve comparability.

The impact of the introduction of business skills units was already having a significant impact on both course content and resource use at Case 2 and Case 1, though less so at Case 3 where student numbers had caused particular delivery problems. The scope of these skills units suggests that they provide a benchmarking exercise of their own.

On an administrative note, given that ranking systems for universities are in place worldwide for various purposes, then, the question of whether some universal ranking system for schools within a faculty would be a worthwhile debate. If this system were implemented then, database and reporting mechanisms across universities would need to be homogenised to allow for accurate and relevant comparisons.

\subsection{Limitations of this study}

As stated earlier, generalisations across the whole Australian university sector are difficult to make given that this project investigated data from only three universities. In addition, there are many more management practices that are conducted in a department/school of accounting that have not been subjected to benchmarking for this project. For example, a comparison of the incentive schemes for research activity across universities would also be a useful exercise to undertake. 


\subsubsection{Future research}

This project was essentially a "pilot-test" for further benchmarking exercises across different disciplines within the business faculties. It is expected that with refinements and improvements to the procedures used in this current project, that future assignments will provide further valid comparisons to ultimately improve student and staff outcomes. With the introduction of the Excellence for Research Australia (ERA) initiative by the Rudd Government, further opportunities will become available to explore to what extent accounting schools research performance will compare in the Australian university sector.

It is also important to note the political ramifications of further benchmarking projects. Although the current investigation was undertaken in a harmonious fashion, this may not be the case if different universities or different disciplines were benchmarked. Collaboration and openness amongst participants are key ingredients for a successful benchmarking exercise. 


\section{References}

Alstete, J.W. (2008). Measurement benchmarks or real benchmarking? An examination of current perspectives. Benchmarking: An International Journal, 15:2, pp. 178-186.

Andersen, B., Henriksen, B and Spjelkavik, I. (2008). Benchmarking applications in public sector principal-agent relationships. Benchmarking: An International Journal, 15:6, pp.723-741.

Bowerman, M., Francis, G., Ball, A. and Fry, J. (2002). The evolution of benchmarking in UK local authorities. Benchmarking: An International Journal, 9:5, pp. 429-449.

Byrne, M. and Flood, B. (2008). Examining the relationships among background variables and academic performance of first year accounting students at an Irish University. Journal of Accounting Education, 26:4, pp.202-212.

Dattakumar, R and Jagadeesh, R. (2003). A review of literature on benchmarking. Benchmarking: An International Journal, 10:3, pp.176-209.

Jones, A. and Sin, S. (2005). Perceptions and priorities of diverse groups of first year accounting students with regard to generic skills/communication. Australian Journal of Accounting Education, 1: 1, pp. 21-50.

Kouzmin, A. Loffler, E., Klages, H and Korac-Kakabadse, N. (1999). Benchmarking and performance measurement in public sectors; Towards learning for agency effectiveness. The International Journal of Public Sector Management, 12:2, pp. 121-144.

Lucas, U. (2003). Contradictions and uncertainties: lecturers' conceptions of teaching introductory accounting. British Accounting Review, 34:3, pp. 183-203.

Lyons, J. (2006). An exploration into factors that impact upon the learning of students from non-traditional backgrounds. Accounting Education: an International Journal, 15:3, pp. 325-334.

Magd, H and Curry, A. (2003). Benchmarking:achieving best value in public-sector organisations. Benchmarking: An International Journal, 10:3, pp.261-286. 
Malgwi, C.A. (2006). Discerning accounting and non-accounting students' perceptions in the first course in Accounting as a proxy for separate course delivery. Global Perspectives on Accounting Education, 3:1, pp. 67-91.

Mathews, M.R. (2004). Accounting Curricula: Does professional accreditation lead to uniformity within Australian bachelor's degree programmes? Accounting Education, 13:1, pp. 71- 89.

Morgan, G. J. (1997). Communication skills required by accounting graduates: practioner and academic perceptions. Accounting Education, 6:2, pp. 93-107.

Punniyamoorthy, M. and Murali, R. (2008). Balanced score for the balanced scorecard: a benchmarking tool. Benchmarking: An International Journal, 15:4, pp. 420-443.

Pursglove, J. and Simpson, M. (2007). Benchmarking the performance of English universities. Benchmarking: An International Journal, 14:1, pp. 102-122.

Smith, M., Whale, J. \& Noronha, A. (2008). Accounting for Journals. Charter, May, pp. 20-22.

Vagnoni, E. and Maran, L. (2008). Public sector benchmarking: an application to Italian health district activity plans. Benchmarking: An International Journal, 15:3, pp. 193-211.

Wynn-Williams, K.L.H. (2005). Performance assessment and benchmarking in the public sector. An example from New Zealand. Benchmarking: An International Journal, 12:5, pp.482-492. 